\title{
Diagnostic and management approach to pouchitis in inflammatory bowel disease
}

\author{
Rocío SEDAN0', Paulina NUÑEZ² and Rodrigo QUERA ${ }^{3}$
}

Received: 16 September 2019 Accepted: 13 December 2019

\begin{abstract}
In patients with ulcerative colitis refractory to medical therapy, total proctocolectomy and posterior ileal-anal pouch anastomosis is the standard surgical therapy. One of the possible complications is pouchitis. Depending on the duration of the symptoms, it can be classified as acute, recurrent, or chronic. The latter, according to the response to therapy, can be defined as antibiotic-dependent or refractory. The treatment of pouchitis is based on the use of antibiotics and probiotics. Thiopurine and biological therapy have been suggested in patients with refractory pouchitis. Special care should be taken in the endoscopic surveillance of these patients, especially if they present risk factors such as dysplasia or previous colorectal cancer, primary sclerosing cholangitis or ulcerative colitis for more than 10 years.
\end{abstract}

HEADINGS - Pouchitis, therapy. Restorative proctocolectomy. Ulcerative colitis.

\section{INTRODUCTION}

In patients with ulcerative colitis (UC) refractory to medical management, the surgical resolution with a total proctocolectomy and subsequent ileal-anal pouch anastomosis is the procedure of choice $^{(1,2)}$. In general, there is a low rate of complications, even though surgical techniques are less invasive with laparoscopic procedures and robotic surgery ${ }^{(3-6)}$. Among the potential complications associated with this surgery, there are suture dehiscence, perianal abscesses, and one of the most frequent, pouchitis. One year after surgery, approximately $20 \%$ of patients develop pouchitis, which can reach an incidence close to $40 \%$ in the fifth year after surgery ${ }^{(2)}$.

In general, episodes of pouchitis are more associated with colectomy due to UC, than to neoplastic or familial polyposic syndromes. In these latter cases, the incidence of pouchitis ranges from $0 \%$ to $11 \%$, which is lower than in colectomies secondary to UC, and could be explained by the immune-mediated etiology of $\mathrm{UC}^{(7-9)}$.

The objective of this review is to evaluate the best approach of pouchitis study and management, being necessary the study with pouchoscopy, for guiding the etiology and determining a more targeted treatment, discussing the different therapeutic alternatives, from the use of antibiotics, probiotics, even considering the use of immunomodulators, corticosteroids and biological therapies in case of refractory pouchitis, as well as the available surgical alternatives and their results ${ }^{(10)}$

\section{Anatomy and function of the pouch}

For a better understanding of this condition, it is necessary to know the different anatomical configurations of the pouch. The most frequent is the J-pouch that uses two small bowel handles to generate the pouch; also, there is an $\mathrm{S}$ and a $\mathrm{W}$ configuration that use three and four handles respectively. The J-pouch has a smaller volume compared to the other configurations $(\mathrm{J}=228 \mathrm{cc}, \mathrm{S}=320 \mathrm{cc}$, and $\mathrm{W}=440 \mathrm{cc}$ ) and it is made from only $30-40 \mathrm{~cm}$ of distal ileum, compared to the $\mathrm{S}$-pouch and the $\mathrm{W}$-pouch which require $50 \mathrm{~cm}$ $\operatorname{each}^{(11,12)}$. (FIGURE 1).

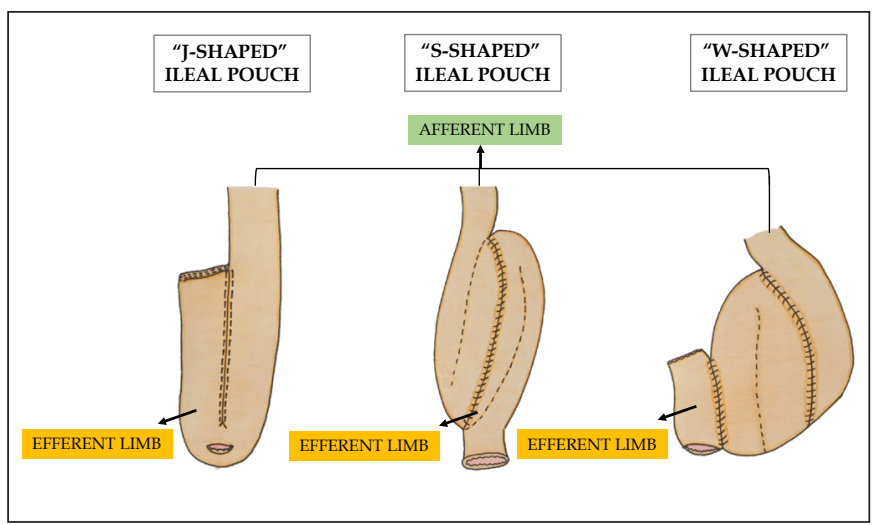

FIGURE 1. Pouch types.

One year after the J-pouch surgery, patients maintain 5-6 stools per day, with 1-2 stools at night; before this, the evacuation frequency may be higher until patients achieve adaptation to the pouch ${ }^{(13)}$.

\section{Concepts and definitions in pouchitis}

Acute pouchitis is characterized by local inflammation of the ileal pouch, which can persist up to four weeks. There is increasing number of bowel movements and lower consistency of the stools, sometimes being associated to mucus and blood. Rectal symptoms such as tenesmus, urgency and even incontinence, can also be seen. Occasionally, patients may also present with systemic manifestations as fever, weight loss and joint involvement ${ }^{(1)}$.

Declared conflict of interest of all authors: none

Disclosure of funding: no funding received

${ }^{1}$ Universidad de Chile, Hospital Clínico, Internal Medicine Departament, Gastroenterology Section, Santiago, Chile. ${ }^{2}$ Universidad de Chile, Hospital San Juan de Dios, Gastroenterology Section, Santiago, Chile. ${ }^{3}$ Clínica Las Condes, Gastroenterology Department, Inflammatory Bowel Disease Program, Santiago, Chile.

Corresponding author: Paulina Nuñez. E-mail: paulinanunez@gmail.com 
The symptoms of pouchitis are nonspecific, and their severity is not always directly related to the endoscopic/histological findings ${ }^{(14)}$. For this reason, the diagnosis must be accompanied by an endoscopic image and histological study ${ }^{(15)}$.

\section{Pathogenesis}

Although the pathogenesis of pouchitis is not yet clear, multiple factors have been involved in its development and evolution. After surgery intestinal mucosa changes, phenomenon known as colonic metaplasia. A significant reduction of the intestinal villi of the pouch area and an increase in the depth of the crypts occur, which correlates with a greater celular proliferation associated with lymphoplasmacytic infiltrate in the lamina propria ${ }^{(16)}$.

Ischemic or mechanical post-surgical phenomena, immunological alterations, and dysbiotics processes have also been evidenced. The latter being observed in the context of good response to antibiotic and probiotic management ${ }^{(8,17)}$.

In the diagnostic evaluation, biopsies should be taken to rule out other pathologies that may present clinically similar to the ones previously described. Secondary causes and other differential diagnoses should be ruled out, such as cuffitis, which is the residual inflammation of the remaining rectum ${ }^{(18-20)}$.

When pouchitis do not respond to antibiotic/probiotic therapy, and the condition persists for more than four weeks, it is called chronic pouchitis, which occurs in $10 \%-15 \%$ of all cases ${ }^{(21,22)}$. Chronic pouchitis can be classified into two entities: chronic antibiotic-dependent pouchitis, where pouchitis recurs at least three times a year after discontinuing antibiotic therapy, and chronic antibiotic-refractory pouchitis, when the condition does not respond to antibiotic therapy ${ }^{(1,23,24)}$.

\section{DIAGNOSTIC APPROACHEMENT}

To distinguish the different etiologies of pouchitis, it is essential to carry out complementary studies to the symptoms described by the patient.

\section{Pouchoscopy}

In clinical practice, pouchoscopy is one of the most useful and practical tools. During this procedure, it is essential to carefully evaluate the reference points of the pouch, including the afferent limb, the pouch, the junction or anastomosis, the efferent loop, and the rectal cuff, documenting each of them with images (FIGURE 2). It is important to describe the presence of edema, erythema, friabil-

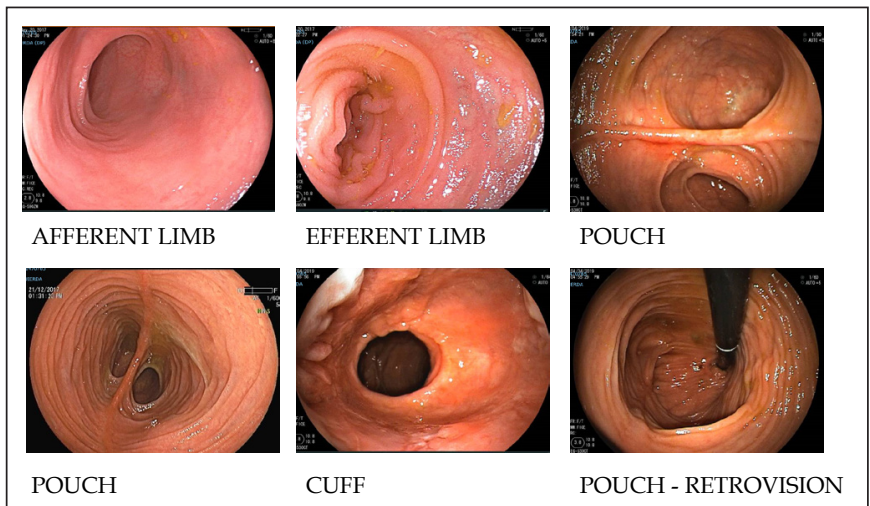

FIGURE 2. Endoscopic images of the pouch. ity, spontaneous bleeding, erosions and ulcerations of the mucosa. Retrovision in the pouch is a safe technique ${ }^{(25-27)}$. According to the compromise of different areas of the pouch, etiological diagnosis of pouchitis can be oriented ${ }^{(22)}$. (FIGURE 3 ).

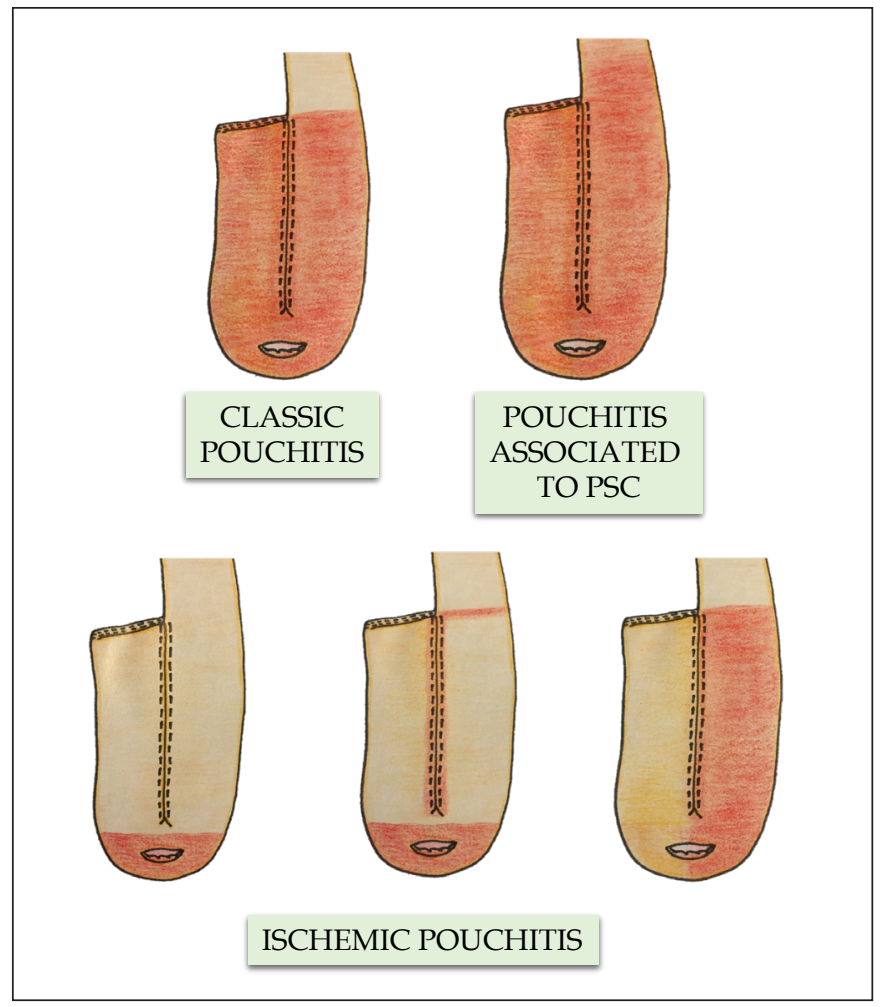

FIGURE 3. Pouchitis patterns.

There are two systems of objective evaluation of the index of inflammatory activity at the pouch level; PDAI (Pouch disease activity index) and PAS (pouchitis activity score). These indices combine clinical symptoms, endoscopic, and histological findings. However, they are not yet fully validated.

\section{Histological study}

As it was described, there is a phenomenon of usual colonic metaplasia accompanied by an infiltrate of inflammatory cells, and in pouchitis, some acute elements such as ulcerations or cryptic abscesses, appears ${ }^{(28)}$. Histology allows differentiating of some secondary causes.

\section{Imaging study}

Computed tomography and magnetic resonance (MR) allow to evaluated the presence of abscesses, strictures, and inflammation of the pouch. MR has a higher sensitivity to detect compromise of the remaining rectum and rule out the presence of perianal disease ${ }^{(11)}$. In a prospective study in patients with a pouch, a good correlation between the findings of the resonance and the endoscopic scores was found ( $\mathrm{r}=0.61 ; P=0.0005)$, with a positive likelihood ratio (LR) of four and a negative LR of $0.18^{(29)}$.

With these elements, we can differentiate whether it is a primary or secondary pouchitis. Primary or idiopathic pouchitis is characterized by the difficulty to investigate a triggering factor of the condition. It is believed that its origin lies in the presence of a mucosal 
dysbiosis that would alter the immune response of the mucosa ${ }^{(30)}$ Ruling out of secondary causes should support its diagnosis.

Secondary pouchitis may have several etiologies being the most frequent:

\section{- Infectious pouchitis}

They are mostly idiosyncratic, with a response rate to therapy close to $80 \%-85 \%$. Classically it compromises the entire pouch. However, some agents must be discarded since they require specific treatment.

Of those refractory or recurrent, the most commonly described microorganism is Clostridioides difficile (C. Diff). The reported incidence is up to $10 \%$ in a North American study, which included symptomatic patients with pouches ${ }^{(31)}$. In this context, it is crucial to perform a microbiological study of fecal material, to be able to guide antibiotic therapy to the specific etiologic agent ${ }^{(10,19,30)}$. Recently published IDSA guidelines suggest to request PCR for C. Diff. alone or associated with toxin A and B and/or Glutamate dehydrogenase $(\mathrm{GDH})$, in patients with high suspicion of $\mathrm{C}$. Diff. infection $^{(32)}$. Most of the time, pouchoscopy can show slight alterations such as edema, loss of the submucosal vascular pattern, friability and less frequently, the classic pseudomembranes ${ }^{(33)}$. In C.Diff. pouchitis that has not responded to standard therapy with vancomycin or fidaxomycin, the therapeutic alternative is the use of fecal microbiota transplantation. These technique has been used in cases of pouchitis with good results ${ }^{(34)}$.

Another important agent to study is cytomegalovirus, which may have a clinical presentation similar to idiopathic pouchitis ${ }^{(35,36)}$. If suspected, pouch tissue samples should be studied with inmunohistochemical staining or PCR. There is better performance with greater number of samples and wen these are obteined from the base of ulcerative lesion ${ }^{(37,38)}$.

Other infectious agents such as Candida sp. have been reported in biopsies of patients with chronic pouchitis ${ }^{(39)}$.

\section{- Immunomediated pouchitis}

This scenario is usually associated with a higher frequency of extraintestinal manifestations and autoimmune disorders, such as pouchitis associated with primary sclerosing cholangitis (PSC) and pouchitis associated with IgG4 disease. Both cases do not respond well to antibiotics and tend to be more severe and chronic. In the case of PSC, patients usually present altered function liver tests and biliary tract compromise in the magnetic resonance cholangiography.

A common finding in the pouchoscopy is the inflammation of the entire pouch and afferent loop ${ }^{(40,41)}$.

Frequent histologic findings in $\mathrm{IgG} 4$ associated pouchitis are the IgG4 plasma cells infiltration of the pouch's mucosa and marked cryptic apoptosis ${ }^{(35)}$. Among the serologic tests, it is possible to find elevated serum IgG4 levels.

Given the increased risk of neoplasia of the pouch, these patients need to enter an endoscopic surveillance program which should be performed every one to two years ${ }^{(42)}$. In both scenarios, immunosuppression is the therapy of choice.

\section{Ischemic pouchitis}

When the etiology suspected is ischemia, the usual finding is a characteristic inflammation pattern of the pouch, compromising only the efferent loop and respecting the afferent loop ${ }^{(43)}$. These cases are usually related to post-surgical anatomical alterations, such as lack of irrigation of the distal ileum or, excessive tension over the mesentery. The classic histological findings are hemosiderin deposits in the endothelium, as a marker of the increased oxidative stress at this level, which perpetuates the inflammation of the mucosa with the underlying inflammatory bowel disease ${ }^{(43-45)}$.

\section{- Crohn's disease of the pouch}

It can be evidenced immediately after surgery, where histological findings are compatible with Crohn's disease, or it can appear years after surgery, being considered a "de novo" disease. Its clinical presentation can be with any of the phenotypes of classic Crohn's disease, and its management must be aggressive and well-directed to avoid complications ${ }^{(46)}$. Pouch's compromise is usually segmentary, stenosis or fistulas may appear at the ileoanal anastomosis or at the proximal end of the pouch, as well as in the afferent $\operatorname{limb} b^{(47,48)}$. Histology does not always show the classic non-casing granuloma $^{(37,49-52)}$.

\section{- Neoplasia}

The risk of malignancies in patients with a pouch is $0.9 \%$ at five years and $5.1 \%$ at 25 years. The history of dysplasia or colorectal cancer before the pouch are independent risk factors for pouch's neoplasia, with a relative risk of 3.76 for previous dysplasia and 24.69 for previous neoplasia ${ }^{(53)}$. Patients with a pouch must have a screening endoscopy every one to three years ${ }^{(54)}$. In patients with risk factors, such history of UC for more than 10 years, cuffitis, family history of colorectal cancer or PSC, should have endoscopic surveillance with biopsy every one or two years. Patients with previous neoplasia, surveillance should have annual survaillance with particular emphasis on the cuff and the anastomosis area ${ }^{(40,42)}$.

\section{- Irritable pouchitis}

In this scenario, symptoms are similar to acute pouchitis; however, no lesions are found in the pouch. It is a manifestation of irritable bowel syndrome; which treatment is based on tricyclic and antispasmodic antidepressants ${ }^{(55)}$.

\section{TREATMENT}

Despite the progress of available therapies, there is still a lack of evidence to establish prevention and treatment of pouchitis.

\section{Acute pouchitis}

First-line therapy is based on antibiotics, such as ciprofloxacin and metronidazole, for 14 days ${ }^{(56,57)}$. However, these recommendations are based on low-quality evidenced studies with a small number of patients ${ }^{(58)}$. One study administered ciprofloxacin 1000 $\mathrm{mg} /$ day to seven patients, and metronidazole $20 \mathrm{mg} / \mathrm{kg} /$ day to nine patients, observing that in the first group 100\% achieved clinical remission vs 33\% (3/9 patients) in the second group. Regarding adverse events, they were only observed in the metronidazole group (nausea, vomiting, dysgeusia and transient peripheral neuropathy) in three of the nine patients ${ }^{(59,60)}$.

A study that compared rifaximin vs placebo showed that only $25 \%(2 / 8)$ of patients receiving rifaximin achieved endoscopic remission at week four of treatment, vs $0 \%(0 / 10)$ of those receiving placebo. Adverse events were documented in six of eight patients in the first group vs five of 10 patients in the placebo group including diarrhea, flatulence, nausea, proctalgia, vomiting, thirst, candida infection, upper respiratory tract infection, increased liver enzymes, and cluster headache ${ }^{(58)}$. 
When there is intolerance to antibiotics, the use of budesonide enemas $(2 \mathrm{mg} / 100 \mathrm{~mL})$ for six weeks has been considered. The response to enemas and metronidazole was evaluated in a doubleblind study. When comparing both strategies, there were no differences in the endoscopic and histological response(61).

It is known that the use of NSAIDs in inflammatory bowel disease should be avoided due to the risk of reactivation of the disease. In a study that included 17 patients with recurrent pouchitis, it was demonstrated that the suspension of these drugs allowed a significant reduction in the PDAI index, and an increase in the quality of life index $(P<0.02 \text { and }<0.05 \text { respectively })^{(62)}$.

\section{Chronic pouchitis}

The treatment of chronic pouchitis is, above all, empirical since quality studies are lacking. Around $5 \%-15 \%$ of patients can progress to chronicity. The first therapeutic approach is the use of antibiotics for periods longer than four weeks. Rifaximin, is the antibiotic of choice as maintenance therapy given its safety profile compared to other antibiotics ${ }^{(63)}$. Some studies have proposed to study the pouch's microbiota and thus identifying the best antibiotic agent to be used in each patient as a personalized treatment strategy ${ }^{(64-6)}$. Alternative treatments suggest the use of ciprofloxacin followed by rifaximin, metronidazole, or tinidazole, for a variable period ${ }^{(65-67)}$.

Through a meta-analysis, it was possible to evaluate the different probiotics used in patients with pouchitis; showing that there is little evidence available regarding dosing and the ideal treatment length, concluding that there is a need of long-term studies to assess the real impact of probiotics in pouchitis ${ }^{(68)}$.

The probiotic VSL \# 3 has the highest number of studies, proving to be effective over placebo, but with a low level of evidence. Eighty-five percent (34/40) of patients who received VLS \# 3 (2 sachets/day $=600$ billion bacteria) maintained remission for 9 to 12 months compared to $3 \%(1 / 36)$ of patients who received placebo (RR 20.24; 95\% CI 4.28 to 95.81$)^{(68)}$. Two percent (1/40) of participants who received VSL \# 3 had an adverse event (abdominal pain, vomiting, and diarrhea), compared with $0 \%(0 / 36)$ of the participants who received placebo ${ }^{(56,68-70)}$.

Other studies with probiotics, such as Lactobacillus rhamnosus supplementation for three months, achieved changes in the bacterial flora of the pouch, however, there was no significant change in clinical or endoscopic response ${ }^{(71)}$.

Chronic antibiotic refractory pouchitis has challenging management, and there are no randomized studies that provide a better quality of evidence about treatment. Steroid therapy with budesonide $9 \mathrm{mg} /$ day has been used for eight weeks, showing that four out of five patients achieved clinical and endoscopic improvement, without reporting adverse effects. In an Italian group of 20 patients, $75 \%$ achieved clinical remission and improvement in their quality of life with $P<0.001^{(72,73)}$.

Biological therapy has been used as a rescue treatment in those patients who have not responded to antibiotic therapy ${ }^{(74)}$. In a retrospective Belgian study that included 28 patients with refractory pouchitis treated with Infliximab $5 \mathrm{mg} / \mathrm{kg}$ every eight weeks, showed that $88 \%$ presented a clinical response at 10 weeks, which was maintained in $56 \%$ of patients at 20 weeks $^{(75)}$. A canadian cohort of 42 patients, of whom 26 had refractory pouchitis and 16 Crohn's disease of the pouch, using infliximab $62.6 \%$ achieved partial clinical response and $29.6 \%$ a complete clinical response ${ }^{(76)}$. For instance, infliximab in maintenance dose for at least one year, has shown to maintain clinical remission in $71.4 \%$ of patients, including the remission of extraintestinal manifestations ${ }^{(77)}$.

Concerning adalimumab, there is a double-blind, multicenter study of patients with refractory pouchitis, who were randomized to adalimumab as induction therapy vs placebo. Of a total of 13 patients, only 9 of them managed to complete the 12 weeks of the study, so it was not possible to establish clinical or endoscopic differences in these two groups ${ }^{(78)}$.

In a systematic review, which included 313 patients with inflammatory complications of the pouch (194 with infliximab and 119 with adalimumab) it was shown that when comparing Crohn's disease of the pouch vs refractory pouchitis, the effectiveness of the therapy was markedly superior for the first group 0.64 vs 0.1 with $P=0.06^{(79)}$.

Experience with vedolizumab comes from a multicenter retrospective cohort study of five American academic centers with a total of 83 patients followed for 1.3 years on average (maximum 2.1 years). Clinical response was observed in $71.1 \%$ of cases, with remission achieved in only $19.3 \%$ of these. The endoscopic response rate was $54.1 \%$, but with mucosal healing of only $17.6 \%$. Thirtysix-point one percent suspended vedolizumab for clinical reasons, three patients for infusion reactions and another three for serious adverse events (C. Diff., norovirus and one patient with an abscess that required laparoscopic drainage $)^{(80)}$.

Regarding ustekinumab, there is a retrospective study of four American centers with a total of 56 patients ( 47 with Crohn's disease of the pouch and nine with chronic pouchitis). Of all patients, $73 \%$ had previusly used an anti TNF or vedolizumab. In Crohn`s group, $83 \%$ demostrated clinical response after induction. An elevated BMI and being male were risk factors for inadequate response $^{(81)}$. A second study included 42 patients with chronic antibiotic refractory pouchitis, $50 \%$ of whom had previously used biological therapy or immunomodulators. Twelve of the 24 $(50 \%)$ patients achieved a post-induction clinical response with ustekinumab. Pouchoscopy was performed in 13 patients, in whom there was a decrease in PDAI from 5 to 4 points with $P=0.016{ }^{(82)}$.

When immune-mediated pouchitis, or Crohn's pouchitis, is investigated, the treatment of choice is immunosuppressive therapy, either with corticosteroids, immunomodulators, or in some cases, biological therapy with a good response as described in the treatment of refractory pouchitis ${ }^{(83,84)}$.

\section{CONCLUSION}

In patients with UC refractory to medical therapy, total proctocolectomy and subsequent ileal-anal pouch anastomosis remains the therapy of choice. Pouchitis is the most frequent complication in this group of patients, and the initial management is with antibiotics. However, a percentage of these patients may present with chronic or refractory pouchitis, and it is necessary to rule out secondary causes and define the best therapeutic strategy. Management algorithm attached in FIGURE 4. 


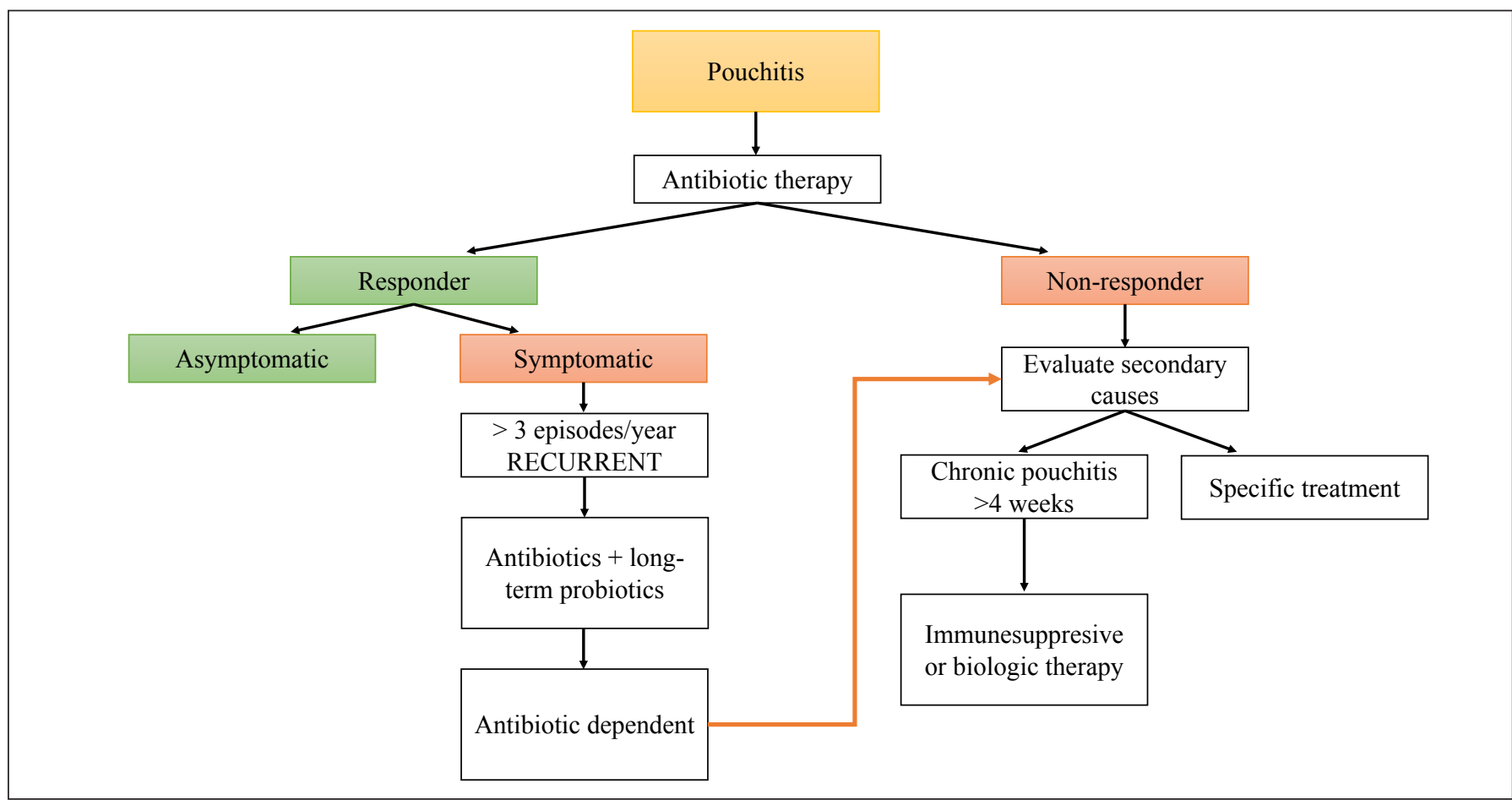

FIGURE 4. Management algorithm.

\section{Authors' contribution}

Sedano R, Nuñez P: review of literature and writing the text and final text approval. Quera R: writing the text, aprovement the final version and final text approval.

\section{Orcid}

Rocío Sedano: 0000-0002-3311-638X.

Paulina Nuñez: 0000-0003-3727-1851.

Rodrigo Quera: 0000-0001-5854-0526.

Sedano R, Nuñez P, Quera R. Abordagem diagnóstica e de manuseio da pouchite em doença inflamatória intestinal. Arq Gastroenterol. 2020;57(1):100-6.

RESUMO - Em pacientes com colite ulcerativa refratária à terapia médica, a proctocolectomia total e anastomose de bolsa ileal-anal posterior é a terapia cirúrgica padrão. Uma das possíveis complicações é a pouchite. Dependendo da duração dos sintomas, pode ser classificado como aguda, recorrente ou crônica. Esta última, de acordo com a resposta à terapia, pode ser definida como dependente de antibióticos ou refratária a eles. O tratamento da pouchite baseia-se no uso de antibióticos e probióticos. A thiopurina e a terapia biológica têm sido sugeridas em pacientes com pouchite refratária Um cuidado especial deve ser tomado na vigilância endoscópica desses pacientes, especialmente se apresentarem fatores de risco, como displasia ou câncer colorretal anterior, colangite esclerosante primária ou colite ulcerativa por mais de 10 anos.

DESCRITORES - Pouchite, terapia. Proctocolectomia restauradora. Colite ulcerativa.

\section{REFERENCES}

1. Sandborn WJ. Pouchitis: definition, risk factors, frequency, natural history, classification and public health perspective. In: McLeod RS (ed) Trends in Inflammatory Bowel Disease Terapy, 1996. Hingham, MA, USA: Kluwer Academic Publishers, 1997.

2. Lepistö A, Luukkonen P, Järvinen HJ. Cumulative failure rate of ileal pouch-anal anastomosis and quality of life after failure. Dis Colon Rectum. 2002;45:1289-94.

3. Ishii H, Kawai K, Hata K, Shuno Y, Nishikawa T, Tanaka T, et al. Comparison of Functional Outcomes of Patients Who Underwent Hand-Sewn or Stapled Ileal Pouch-Anal Anastomosis for Ulcerative Colitis. Int Surg. 2015;100:1169-76.

4. Homma S, Kawamata F, Shibasaki S, Kawamura H, Takahashi N, Taketomi A. Does reduced-port laparoscopic surgery for medically uncontrolled ulcerative colitis do more harm than good? Asian J Endosc Surg. 2016;9:24-31.

5. Pedraza R, Patel CB, Ramos-Valadez DI, Haas EM. Robotic-assisted laparoscopic surgery for restorative proctocolectomy with ileal $\mathrm{J}$ pouch-anal anastomosis. Minim Invasive Ther Allied Technol. 2011;20:234-9.
6. Miller AT, Berian JR, Rubin M, Hurst RD, Fichera A, Umanskiy K. Robotic-assisted proctectomy for inflammatory bowel disease: a case-matched comparison of laparoscopic and robotic technique. J Gastrointest Surg. 2012;16:587-94.

7. Hata K, Yamamoto Y, Kiyomatsu T, Tanaka T, Kazama S, Nozawa H, et al Hereditary gastrointestinal cancer. Surg Today. 2016;46:1115-22.

8. Lohmuller JL, Pemberton JH, Dozois RR, Ilstrup D, van Heerden J. Pouchitis and extraintestinal manifestations of inflammatory bowel disease after ileal pouch-anal anastomosis. Ann Surg. 1990;211:622-7.

9. McLaughlin SD, Clark SK, Tekkis PP, Nicholls RJ, Ciclitira PJ. The bacteria pathogenesis and treatment of pouchitis. Therap Adv Gastroenterol. 2010;3:335-48.

10. Segal JP, Ding NS, Worley G, Mclaughlin S, Preston S, Faiz OD, et al. Systematic review meta-analysis: The management of chronic refractory pouchitis with an evidence-based treatment algorithm. Aliment Pharmacol Ther. 2017;45:581-92.

11. Quinn K, Lightner A, Faubion W, Raffals L. A comprehensive approach to pouch disorders. Inflamm Bowel Dis. 2019;25:460-71. 
12. Sagar P, Holdsworth P, Godwin P, Quirke P, Smith A, Johnston D. Comparison of Triplicated (S) and Quadruplicated (W) Pelvic Ileal Reservoirs. Gastroenterology. 1992;102:520-8.

13. Lightner AL, Mathis KL, Dozois EJ, Hahnsloser D, Loftus EV Jr, Raffals LE, et al. Results at up to 30 years after ileal pouch-anal anastomosis for Chronic ulcerative colitis. Inflamm Bowel Dis. 2017;23:781-90.

14. Ben-Bassat O, Tyler AD, Xu W, Kirsch R, Schaeffer DF, Walsh J, et al. Ileal pouch symptoms do not correlate with inflammation of the pouch. Clin Gastroenterol Hepatol. 2014;12:831-7.

15. Shen B, Achkar JP, Lashner BA, Ormsby AH, Remzi FH, Bevins CL, Brzezinski A, Petras RE, Fazio VW. Endoscopic and histologic evaluation together with symptom assessment are required to diagnose pouchitis. Gastroenterology. 2001;121:261-7.

16. Schieffer K, Williams E, Yochum G, Koltun W. Review article: the pathogenesis of pouchitis. Aliment Pharmacol Ther. 2016;44:817-35.

17. Fukushima T, Sugita A, Koganei K, Fujii S, Shinozaki M. Staple-line ulcer in the ileal reservoir following restorative proctocolectomy. Surg Today. 2002;32:118-22.

18. Shen B, Achkar JP, Lashner BA, Ormsby AH, Brzezinski A, Soffer EE, et al. Irritable pouch syndrome: a new category of diagnosis for symptomatic patients with ileal pouch-anal anastomosis. Am J Gastroenterol. 2002;97:972-7.

19. Sandborn WJ, Tremaine WJ, Batts KP, Pemberton JH, Phillips SF. Pouchitis after ileal pouch-anal anastomosis: a Pouchitis Disease Activity Index. Mayo Clin Proc. 1994;69:409-15.

20. Wu B, Lian L, Li Y. Clinical course of cuffitis in ulcerative colitis patients with restorative proctocolectomy and ileal pouch-anal anastomoses. Inflamm Bowel Dis. 2013;19:404-10.

21. Pardi DS, Shen B. Endoscopy in the management of patients after ileal pouch surgery for ulcerative colitis. Endoscopy. 2008;40:529-33.

22. Shen B. Pouchitis: what every gastroenterologist needs to know. Clin Gastroenterol Hepatol. 2013;11:1538-49.

23. Shen B. Diagnosis and management of postoperative ileal pouch disorders. Clin Colon Rectal Surg. 2010;23:259-68.

24. Zhaoxiu Liu, Hui Song, Bo Shen. Pouchitis: prevention and treatment. Curr Opin Clin Nutr Metab Care. 2014;17: 489-95.

25. Cima RR, Pemberton JH. Medical and surgical management of chronic ulcerative colitis. Arch Surg. 2005;140:300-10.

26. Fukushima K, Fujii H, Yamamura T, Sugita A, Kameoka S, et al. Pouchitis atlas for objective endoscopic diagnosis. J Gastroenterol. 2007;42:799-806.

27. Bhattacharya A, Shen B Regueiro M. Endoscopy in postoperative patients with Crohn's disease or ulcerative colitis. Does it translate to better outcomes? Gastrointest Endosc Clin N Am. 2019;29:487-514.

28. Navaneethan U, Shen B. Diagnosis and management of pouchitis and ileoanal pouch dysfunction. Curr Gastroenterol Rep. 2010;12:485-94.

29. Sahi KS, Lee KS; Moss A, Yee E, Allard F, Brook A, et al. MR enterography of the ileoanal pouch: descriptive radiologic analysis with endoscopic and pathologic correlation. AJR Am J Roentgenol. 2015;205:478-84.

30. Batista D, Raffals L. Role of intestinal bacteria in the pathogenesis of pouchitis. Inflamm Bowel Dis. 2014;20:1481-6.

31. Seril DN, Ashburn JH, Lian L, Shen B. Risk factors and management of refractory or recurrent clostridium difficile infection in ileal pouch patients. Inflamm Bowel Dis. 2014;20:2226-33.

32. McDonald LC, Gerding DN, Johnson S, Bakken JS, Carroll KC, Coffin SE, et al Clinical Practice Guidelines for Clostridium difficile Infection in Adults and Children: 2017 Update by the Infectious Diseases Society of America (IDSA) and Society for Healthcare Epidemiology of America (SHEA). Clin Infect Dis. 2018;66:1-48.

33. Issa M, Vijayapal A, Graham MB, Beaulieu DB, Otterson MF, Lundeen S, et al. Impact of Clostridium difficile on inflammatory bowel disease. Clin Gastroenterol Hepatol. 2007:5:345-51.

34. Patel LN, Schairer J, Shen B. Fecal transplantation therapy for Clostridium difficile associated pouchitis. Int J Colorectal Dis. 2014;29:263-4.

35. Seril DN, Yao Q, Shen B. The association between autoimmunity and pouchitis. Inflamm Bowel Dis. 2014;20:378-88.

36. Zidar N, Ferkolj I, Tepeš K, Štabuc B, Kojc N, Uršič T, et al. Diagnosing cytomegalovirus in patients with inflammatory bowel disease by immunohistochemistry or polymerase chain reaction? Virchows Arch. 2015;466:533-9.

37. McCurdy JD, Loftus EV, Tremaine WJ, Smyrk TC, Bruining DH, Pardi DS, et al. Cytomegalovirus infection of the ileoanal pouch: clinical characteristics and outcomes. Inflamm Bowel Dis. 2013;19:2394-9.

38. Araujo Miguez A, Herrera Justiniano JM, Carnerero EL, Salado CT, de la Cruz Ramírez MD, Martínez Risquez MT, et al. Pouchitis associated with citomegalovirus infection: a case study. Inflamm Bowel Dis. 2013;19:65-6.

39. Navaneethan U, Shen B. Secondary pouchitis: those with identifiable etiopathogenetic or triggering factors. Am J Gastroenterol. 2010;105:51-64.
40. Nuñez P, Quera P, Gomollón F. Colangitis esclerosante primaria y enfermedad inflamatoria intestinal: interrelación intestino - hígado. Gastroenterol Hepatol. 2019;42:316-25.

41. Shen B, Bennett AE, Navaneethan U, Lian L, Shao Z, Kiran RP, Fazio VW, Remzi FH. Primary sclerosing cholangitis is associated with endoscopic and histologic inflammation of the distal afferent limb in patients with ileal pouch anal anastomosis. Inflamm Bowel Dis. 2011;17:1890-900.

42. Khan F, Shen B. Inflammation and neoplasia of the pouch in Inflammatory bowel disease. Curr Gastroenterol Rep. 2019;21:10-7.

43. Shen B, Plesec TP, Remer E, Kiran P, Remzi FH, Lopez R, Fazio VW, Goldblum JR. Asymmetric endoscopic inflammation of the ileal pouch: a sign of ischemic pouchitis? Inflamm Bowel Dis. 2010;16:836-46.

44. Laake KO, Line PD, Grzyb K, Aamodt G, Aabakken L, Røset A, et al. Assessment of mucosal inflammation and blood flow in response to four weeks' intervention with probiotics in patients operated with a J configurated ileal pouch-anal anastomosis (IPAA). Scand J Gastroenterol. 2004;39:1228-35.

45. Muhtaseb MS, Talwar D, Duncan A, St J O'reilly D, McKee RF, Anderson JH, et al. Free radical activity and lipid soluble antioxidant vitamin status in patients with long-term ileal pouch-anal anastomosis. Colorectal Dis. 2009;11:67-72.

46. Li Y, Wu B, Shen B. Diagnosis and differential diagnosis of Crohn's disease of the ileal pouch. Curr Gastroenterol Rep. 2012;14:406-13.

47. Wolf JM, Achkar JP, Lashner BA, Delaney CP, Petras RE, Goldblum JR, et al. Afferent limb ulcers predict Crohn's disease in patients with ileal pouch-anal anastomosis. Gastroenterology. 2004;126:1686-91.

48. Sagar PM, Dozois RR, Wolff BG. Long-term results of ileal pouch-anal anastomosis in patients with Crohn's disease. Dis Colon Rectum. 1996;39:893-8.

49. Casadesus D, Tani T, Wakai T, Maruyama S, Iiai T, Okamoto H, et al. Possible role of human cytomegalovirus in pouchitis after proctocolectomy with ileal pouch-anal anastomosis in patients with ulcerative colitis. World J Gastroenterol. 2007;13:1085-9.

50. Jiang W, Goldblum JR, Lopez R, Lian L, Shen B. Increased crypt apoptosis is a feature of autoimmune associated chronic antibiotic refractory pouchitis. Dis Colon Rectum. 2012;55:549-57.

51. Navaneethan U, Bennett AE, Venkatesh PG, Lian L, Hammel J, Patel V, et al. Tissue infiltration of IgG4+ plasma cells in symptomatic patients with ileal pouch-anal anastomosis. J Crohns Colitis. 2011;5:570-6.

52. Agarwal S, Stucchi AF, Dendrinos K, Cerda S, O'Brien MJ, Becker JM, et al. Is pyloric gland metaplasia in ileal pouch biopsies a marker for Crohn's disease? Dig Dis Sci. 2013;58:2918-25.

53. Derikx LA, Kievit W, Drenth JP, de Jong DJ, Ponsioen CY, Oldenburg B, et al. Prior colorectal neoplasia is associated with increased risk of ileoanal pouch neoplasia in patients with inflammatory bowel disease. Gastroenterology. 2014;146:119-28.

54. Gonzalo DH, Collinsworth AL, Liu X. Common inflammatory disorders and neoplasia of the ileal pouch: A review of histopathology. Gastroenterology Res. 2016;9:29-38.

55. Makkar R, Graff LA; Bharadwaj S, Lopez R, Shen B. Psychological factors in irritable pouch syndrome and other pouch disorders. Inflamm Bowel Dis. 2015;21:2815-24.

56. Gionchetti P, Rizzello F, Venturi A, Brigidi P, Matteuzzi D, Bazzocchi G, et al. Oral bacteriotherapy as maintenance treatment in patients with chronic pouchitis: a double-blind, placebo-controlled trial. Gastroenterology. 2000;119:305-9.

57. Isaacs KL, Sandler RS, Abreu M, Picco MF, Hanauer SB, Bickston SJ, et al. Rifaximin for the treatment of active pouchitis: a randomized, double-blind, placebo-controlled pilot study. Inflamm Bowel Dis. 2007;13:1250-5.

58. Nguyen N, Zhang B, Holubar SD, Pardi DS, Singh S. Treatment and prevention of pouchitis after ileal pouch-anal anastomosis for chronic ulcerative colitis. Cochrane Database Syst Rev. 2019;5:CD001176.

59. Shen B, Achkar JP, Lashner BA, Ormsby AH, Remzi FH, Brzezinski A, et al. A randomized clinical trial of ciprofloxacin and metronidazole to treat acute pouchitis. Inflam Bowel Dis. 2001;7:301-5.

60. Singh S, Stroud AM, Holubar SD, Sandborn WJ, Pardi DS. Treatment and prevention of pouchitis after ileal pouch-anal anastomosis for chronic ulcerative colitis. Cochrane Database Syst Rev. 2015;23:1-4.

61. Sambuelli A, Boerr L, Negreira S, Gil A, Camartino G, Huernos S, et al. Budesonide enema in pouchitis a double blind, double dummy, controlled trial. Aliment Pharmacol Ther. 2002;16:27-34.

62. Shen B, Fazio VW, Remzi FH, Bennett AE, Lopez R, Lavery IC, et al. Effect of withdrawal of nonsteroidal anti-inflammatory drug use on ileal pouch disorders. Dig Dis Sci. 2007;52:3321-8.

63. Shen B, Remzi FH, Lopez AR, Queener E. Rifaximin for maintenance therapy in antibiotic-dependent pouchitis. BMC Gastroenterol. 2008;8:26.

64. McLaughlin SD, Clark SK, Shafi S, Petrovska L, Tekkis PP, Ciclitira PJ, et al. Fecal coliform testing to identify effective antibiotic therapies for patients with antibiotic resistant pouchitis. Clin Gastroenterol Hepatol. 2009;7:545-8. 
65. Abdelrazeq AS, Kelly SM, Lund JN, Leveson SH. Rifaximin-ciprofloxacin combination therapy is effective in chronic active refractory pouchitis. Colorectal Dis. 2005;7:182-6.

66. Mimura T, Rizzello F, Helwig U, Poggioli G, Schreiber S, Talbot IC, et al. Fourweek open-label trial of metronidazole and ciprofloxacin for the treatment of recurrent or refractory pouchitis. Aliment Pharmacol Ther. 2002;16:909-17.

67. Shen B, Fazio VW, Remzi FH, Bennett AE, Lopez R, Brzezinski A, et al. Combined ciprofloxacin and tinidazole therapy in the treatment of chronic refractory pouchitis. Dis Colon Rectum. 2007;50:498-508.

68. Elahi B, Nikfar S, Derakhshani S, Vafaie M, Abdollahi M. On the benefit of probiotics in the management of pouchitis in patients underwent ileal pouch anal anastomosis: a meta-analysis of controlled clinical trials. Dig Dis Sci. 2008;53:1278-84.

69. Mimura T, Rizzello F, Helwig U, Poggioli G, Schreiber S, Talbot IC, et al. Once daily high dose probiotic therapy (VSL\#3) for maintaining remission in recurrent or refractory pouchitis. Gut. 2004;53:108-14.

70. Holubar SD, Cima RR, Sandborn WJ, Pardi DS. Treatment and prevention of pouchitis after ileal pouch-anal anastomosis for chronic ulcerative colitis. Cochrane Database Syst Rev. 2010;6:CD001176.

71. Kuisma J, Mentulla S, Jarvinen H, Kahri A. Saxelin M, Farkkla M. Effect of lactobacillus rhamnosis GG on ileal pouch inflammation and microbial flora. Aliment Pharmacol Ther. 2003;17:509-15.

72. Cabriada Nuño JL, Hernandez Martín A, Bernal Martínez A, Zabalza Estévez J Oral budesonide in the treatment of chronic refractory pouchitis. Gastroenterol Hepatol. 2008;31:485-9.

73. Gionchetti P, Rizello F, Poggioli G, Pierangeli F, Laureti S, Morselli C, et al. Oral budesonide in the treatment of chronic refractory pouchitis. Aliment Pharmacol Ther. 2007;25:1231-6.

74. Papamichael K, Lin S, Moore M, Papaioannou G, Sattler L Cheifetz AS. Infliximab in inflammatory bowel disease. Ther Adv Chronic Dis. 2019;10:1-15.
75. Ferrante M, D’Haens G, Dewit O, Baert F, Holvoet J, Geobes K, et al. Efficacy of infliximab in refractory pouchitis and Crohn's disease-related complications of the pouch: a Belgian case series. Inflamm Bowel Dis. 2010;16:243-9.

76. Kelly OB, Rosenberg M, Tyler AD, Stempak JM, Steinhart AH, Cohen Z, et al. infliximab to treat refractory inflammation after pelvic pouch surgery for ulcerative colitis. J Crohns Colitis. 2016;10:410-7.

77. Viazis N, Giakoumis M, Koukouratos T, Anastasiou J, Katopodi K, Kechagias G, et al. Long term Benefit of one year infliximab administration for the treatment of chronic refractory pouchitis. J Crohns Colitis. 2013;7:457-60.

78. Kjaer MD, Qvist N, Nordgaard-Lassen I, Christensen LA, Kjeldsen J. Adalimumab in the treatment of chronic pouchitis. A randomized double-blind, placebo-controlled trial. Scand J Gastroenterol. 2019;54:188-93.

79. Huguet M, Pereira B, Goutte M, Goutorbe F, Dubois A, Bonmelaer G, et al. Systematic review with meta-analysis: Anti- TNF therapy in refractory pouchitis and Crohn's disease like complications of the pouch after ileal pouch anal anastomosis following colectomy for ulcerative colitis. Inflamm Bowel Dis. 2018;24:261-8.

80. Gregory M, Weaver KN, Hoversten P, Hicks SB, Patel D, Ciorba MA, et al. Efficacy of vedolizumab for refractory pouchitis of the ileo- anal pouch: results from a multicenter US Cohort. Inflamm Bowel Dis. 2019;25:1569-76.

81. Weaver KN, Gregory M, Syal G, Hicks SB, Patel D, Christophi G. Ustekinumab is effective for the treatment of Crohn's disease of the pouch in a multicenter cohort. Inflamm Bowel Dis. 2019;25:767-74.

82. Ollech JE, Rubin DT, Glick L, Weisshof R, EL Jurdi K, Israel A, et al. Ustekinumab is effective for the treatment of chronic antibiotic-refractary pouchitis Dig Dis Sci. 2019;64:3596-601.

83. Shen B. Crohn's disease of the ileal pouch: reality, diagnosis, and management. Inflamm Bowel Dis. 2009; 15:284-94.

84. Haveran LA, Sehgal R, Poritz LS, McKenna KJ, Stewart DB, Koltun WA. Infliximab and/or azathioprine in the treatment of Crohn's disease like complications after IPAA. Dis Colon Rectum. 2011;54:15-20. 